\title{
BMJ Open Impact of incarceration on \\ cardiovascular disease risk factors: a systematic review and meta-regression on weight and BMI change
}

\author{
Constantin Bondolfi (D) , ${ }^{1}$ Patrick Taffe, ${ }^{2}$ Aurélie Augsburger, ${ }^{3}$ Cécile Jaques, ${ }^{4}$ \\ Mary Malebranche, ${ }^{1,5}$ Carole Clair (D) , ${ }^{3}$ Patrick Bodenmann ${ }^{1}$
}

To cite: Bondolfi C, Taffe P, Augsburger A, et al. Impact of incarceration on cardiovascular disease risk factors: a systematic review and meta-regression on weight and BMI change. BMJ Open 2020;10:e039278. doi:10.1136/ bmjopen-2020-039278

- Prepublication history and additional material for this paper are available online. To view these files, please visit the journal online (http://dx.doi. org/10.1136/bmjopen-2020039278).

Received 13 April 2020 Revised 24 August 2020 Accepted 26 August 2020

Check for updates

(C) Author(s) (or their employer(s)) 2020. Re-use permitted under CC BY-NC. No commercial re-use. See rights and permissions. Published by BMJ.

For numbered affiliations see end of article.

Correspondence to Dr Constantin Bondolfi; constantin.bondolfi@unisante.ch

\section{ABSTRACT}

Objective Cardiovascular disease is an underappreciated issue in prison medicine. Recent studies have revealed a higher prevalence of cardiovascular disease risk factors (CVDRFs) among individuals in prison, but the impact of incarceration on CVDRFs over time is not well understood. This review aimed to assess available literature and quantify the relationship between incarceration and trends in major CVDRFs in high-income countries.

Design Systematic review following the Preferred Reporting Items for Systematic Reviews and MetaAnalyses statement. Meta-regression on weight change and obesity.

Data sources Medline, Embase, PubMed, Cochrane Central Wiley and Web of Science.

Eligibility criteria for selecting studies Longitudinal studies reporting on the incidence of, or trends in any CVDRF among current or former people in prison over time, in high-income countries.

Data extraction and synthesis Two authors independently screened articles for eligibility, extracted data and assessed quality using an adapted version of the Newcastle-Ottawa Scale. Trends in CVDRFs during and following incarceration were summarised and in those with sufficient data a meta-regression was performed. Results Twenty-six articles were identified. CVDRFs assessed included obesity, hypertension, diabetes, dyslipidaemia, tobacco use, physical inactivity and unhealthy diet. A meta-regression on change in weight during incarceration found a mean increase of $5.3 \mathrm{~kg}$ $(95 \% \mathrm{Cl} 0.5$ to 10.1$)$ and change in body mass index of $1.8 \mathrm{~kg} / \mathrm{m}^{2}(95 \% \mathrm{Cl}-0.9$ to 4.6$)$ at 2 years. Weight gain appeared most pronounced right after entering prison and then plateaued at 2 years. Concerning hypertension, the results were inconclusive, despite a trend towards rising blood pressure or prevalence of hypertension during incarceration, and an increased incidence of hypertension following incarceration. Results are contradictory or inconclusive for the other CVDRFs reviewed.

Conclusion Possible explanations for the association between incarceration and weight include a sedentary lifestyle, unhealthy diet, forced smoking cessation, psychotropic medication use and high levels of stress. Incarceration may be an independent risk factor for cardiovascular disease.
Strengths and limitations of this study

- Our statistical approach (a random-effects metaregression model) allowed us to assess the doseresponse relationship between time spent in prison and weight and body mass index changes.

- The methodology used to assess the relationship between time spent in prison and changes in weight can contribute to a better understanding of the temporal relationship between weight gain and incarceration and help identify key mediating factors.

- The uncertainty in the estimates of the meta regression were high due to the small number of included studies, reflected by the large Cls.

- Substantial heterogeneity between studies, including differences in prison contexts and population characteristics, limited our ability to draw clear conclusions about which factors contribute to the trends in CVDRFs described.

- Findings have limited generalisability to low-income or middle-income countries given they were excluded from the analysis.

\section{INTRODUCTION}

\section{Background}

Cardiovascular disease (CVD) is the leading cause of death worldwide ${ }^{1}$ and among the primary causes of disability. ${ }^{2}$ CVD is also a leading cause of death in people currently or previously incarcerated. ${ }^{3}$ In 2018, in the USA, over 2.1 million people experienced incarceration, amounting to $0.65 \%$ of the US population, nearly five times the rate in the UK. ${ }^{4}$ This disproportionately affects AfricanAmerican men in whom it has been estimated that up to a third have had contact with the prison system. ${ }^{5}$ Furthermore, in high-income countries, the prison population is growing older along with the general population and it is estimated that one-third of the US prison population will be over 55 by $2030 .{ }^{6}$ Like the general population, older people in prison have a different and more complex health 
profile, and in particular, a higher incidence of chronic diseases. ${ }^{7}$ Currently, clinical guidelines ${ }^{8} 9$ and research in prison medicine tend to focus on infectious diseases, substance use, psychiatric disorders and trauma. ${ }^{10}$ With this demographic shift towards older prison populations there is a need to better understand trends in chronic conditions that are expected to emerge.

Recently, there is growing evidence that people in prison experience a high prevalence of CVDRFs including hypertension (HTN), obesity, diabetes and tobacco use, compared with the general population. ${ }^{11-17}$ In the USA, this trend is especially evident among women in prison. ${ }^{18}$ Furthermore, about $80 \%^{19-21}$ of prisoners are smokers, which is 1.7-8 times higher than the general population. ${ }^{22}$ Conversely, other evidence ${ }^{18} 23$ suggests a lower level of obesity among people in prison compared with the general population, challenging the common belief that the prison environment is detrimental to health.

It is unclear whether the prison environment is the cause of health issues or whether it mirrors an overrepresentation of morbid people or people with pre-existing CVD risks factors. ${ }^{12}$ There is a gap of knowledge about the impact of incarceration on the emergence or change in major CVDRFs over time. To address this knowledge gap, this review aims to summarise and quantify, where possible, the relationship between incarceration and trends in major CVDRFs over time including obesity (weight gain), HTN, diabetes, tobacco use, dyslipidaemia, unhealthy diet and physical inactivity in high-income countries.

\section{METHOD}

\section{Literature search}

A literature search was conducted with the assistance of a medical librarian in five databases: Medline Ovid SP (1946 to December 2018), Embase.com (1947 to December 2018), PubMed (1946 to December 2018) with restriction to non-Medline articles, Cochrane Central Wiley and Web of Science Core Collection (1900 to December 2018). All keywords, MeSH and Emtree terms that describe prison, and major CVDRFs were used, including obesity (including the concepts of body mass index (BMI), or weight), HTN, diabetes (DM), dyslipidaemia, tobacco use, physical inactivity and unhealthy diet. The type of study, or population type was not specified at this stage. The detailed search strategy is available in the online supplemental appendix A. Additional studies were identified through a review of all references in the included articles.

\section{Screening articles for eligibility}

Two authors (CB and AA) independently screened articles for eligibility in two phases: 1 ) screening by a title and abstract and 2) a full-text screening. Disagreements that could not be resolved between $\mathrm{CB}$ and $\mathrm{AA}$ were resolved through discussion with a third author (PB).

\section{Inclusion and exclusion criteria}

Studies reporting at least two values of any CVDRFs at two different time points, or studies that described the incidence of any CVDRF, irrespective of the baseline CVDRFs of the population, were included. Only studies conducted in high-income countries were eligible. The full eligibility criteria used during screening can be found in table 1 .

\section{Data extraction}

The data extracted from each article included: study design, study population characteristics (sex, age), time already served at baseline and follow-up duration. In cases where the same study population was used in several studies, only the results of the main study were reported (ie, the one with more participants or CVDRF evaluations). For all studies, we also extracted and reported the first and last value of each CVDRF or its incidence rate. For randomised controlled trials (RCTs), only the values in the control arm were extracted. When needed, study authors were contacted by email to verify their methodology or to request additional data.

\section{Quality appraisal}

The quality of each article was assessed independently by $\mathrm{CB}$ and AA. A quality scale of 1-8 was created based on the Newcastle-Ottawa Scale for quality assessments of cohort studies. ${ }^{24}$ Articles with 1-3 stars were considered of poor quality, 4-6 stars of moderate quality and 7-8 stars of good quality. The scores are indicated with star symbols (*) in table 2 .

\section{Statistical methods}

Findings for all associations between incarceration and individual CVDRFs were reported using descriptive statistics. The data on mean follow-up time, weight and BMI changes from baseline, along with SEs, were extracted and presented on a forest plot with studies sorted according to the mean follow-up time. As the forest plot clearly exhibited both the presence of strong heterogeneity and a dose-response relation of the outcomes with time, we conducted a random-effects meta-regression analysis. Estimation was carried out by restricted maximum likelihood. Based on the regression coefficients, the doseresponse relationship between time spent in prison and each of the outcomes (ie, change in weight and BMI over time) were graphed on scatter plots with the size of the points (or 'bubbles') proportional to the precision of the effect size estimates. A pointwise CI around the regression line was computed. We used Stata V.15 (StataCorp, College Station, Texas, USA) to conduct the statistical analysis. Due to insufficient data, no statistical analysis could be performed on all other CVDRFs assessed in this review.

\section{Patient and public involvement}

Due to the nature of our systematic review (ie, not original research), it was not appropriate or possible to involve patients or the public in the design, conduct, reporting or dissemination plans for our study. 
Table 1 Eligibility criteria

\begin{tabular}{ll}
\hline Inclusion criteria & Exclusion criteria \\
\hline Population & \\
\hline Adults (aged $\geq 18$ years) & $\begin{array}{l}\text { Children or adolescents } \\
\text { Men and women }\end{array}$ \\
$\begin{array}{l}\text { Custody, community correction supervision (eg, probation, } \\
\text { parole) or war prisoner }\end{array}$ \\
Current or ex-prisoners & $\begin{array}{l}\text { Focused only on people in prison with a specific health } \\
\text { condition like chronic infectious diseases (HIV, hepatitis, } \\
\text { etc), mental disease or addiction, unless a control group } \\
\text { exists }\end{array}$ \\
\hline
\end{tabular}

High-income country

Languages

English, French, Spanish, Portuguese, German, Italian

Duration

Minimum 2 weeks follow-up

$<2$ weeks

Study type

Longitudinal or cohort studies prospective or retrospective

Systematic reviews, conference proceedings, book reviews, commentaries, fact sheets, discussion or policy statements

Randomised controlled trials or intervention studies only if a control group exists

Cross-sectional only if compared with previous data from the same population

Outcome

Changes in major CVDRFs levels during or after incarceration at

two independent timepoints

CVDRF, cardiovascular disease risk factors.

\section{RESULTS}

The Preferred Reporting Items for Systematic Reviews and Meta-Analyses flow chart (figure 1) summarises the study selection process. A total of 5494 articles were identified through the prespecified search strategy (see online supplemental appendix A). Twenty-six articles met criteria for inclusion in the final analysis, of which 22 reported on unique study populations. One author ${ }^{25-27}$ published three papers on the same population, and another two authors ${ }^{28-31}$ published two papers.

Ten authors ${ }^{29} 32-40$ were contacted due to missing data or difficulties interpreting study results in the published papers. One ${ }^{40}$ responded that the data were no longer available. Four others were able to share results ${ }^{3334}$ or assist in their interpretation. ${ }^{29}$ The remaining authors could not be reached. A summary of the 22 included studies is provided in table 2. Three studies were rated of good quality, 13 of moderate quality and 4 of poor quality. A table summarising the quality assessments for each article is available in online supplemental appendix B. The majority of studies addressed CVDRFs during incarceration. Only three studies addressed changes in CVDRFs following incarceration. 363941

In the following sections, all studies followed by a star ('*') reported a statistically significant value $(\mathrm{p}<0.05)$ for the difference between baseline and end of follow-up for the CVDRF of interest.

\section{Hypertension}

Seven studies addressed the impact of incarceration on blood pressure (BP). ${ }^{30} 32383942-44$ In four studies the mean level of BP rose during incarceration. ${ }^{32} 384243$ Two studies $^{3038}$ found a non-significant increase in the number of people in prison suffering from HTN during incarceration $(+2.5 \%$ and $+0.6 \%$, respectively $)$. One study, derived from a US cohort followed for 5 years after incarceration, reported a $12 \%$ cumulative incidence of HTN among ex-prisoners compared with 7\% among non-exprisoners. ${ }^{39 *}$ This difference was particularly marked in those who were less educated and in black men. One study focusing on the concept of crowding found that people in prison who moved from individual cells to dormitory-style cells experienced a small but statistically significant mean rise in systolic $\mathrm{BP}$ of $2.6 \mathrm{~mm} \mathrm{Hg} .{ }^{42^{*}}$ However, this effect was reversible when they moved back to an individual cell. In contrast, one Japanese study showed a significant decrease in $\mathrm{BP}^{44^{*}}$ during incarceration over a 1-year period.

\section{Diabetes}

Five studies addressed trends in diabetes during incarceration. ${ }^{35} 39{ }^{45-47}$ Three reported an improvement in 


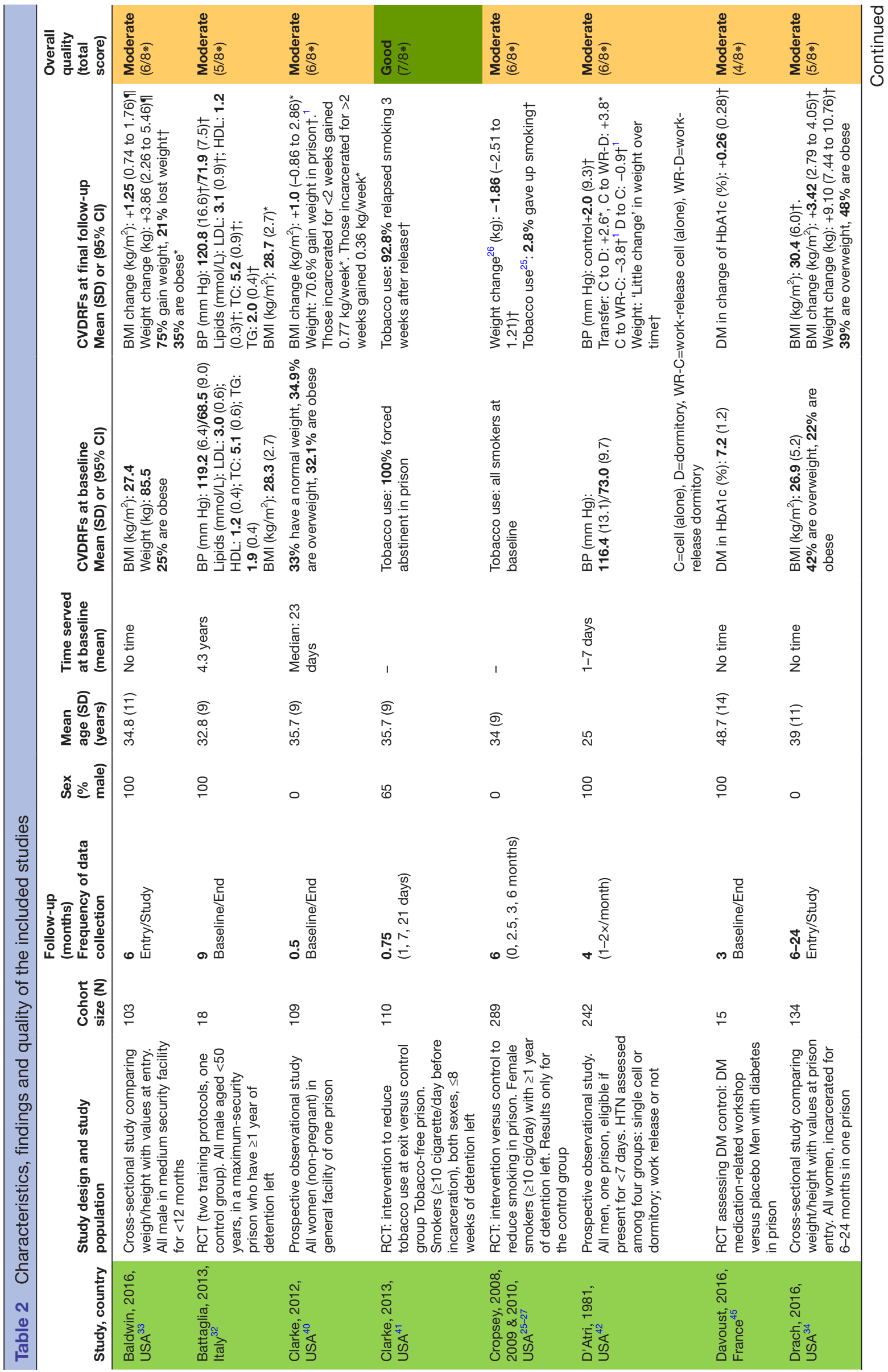




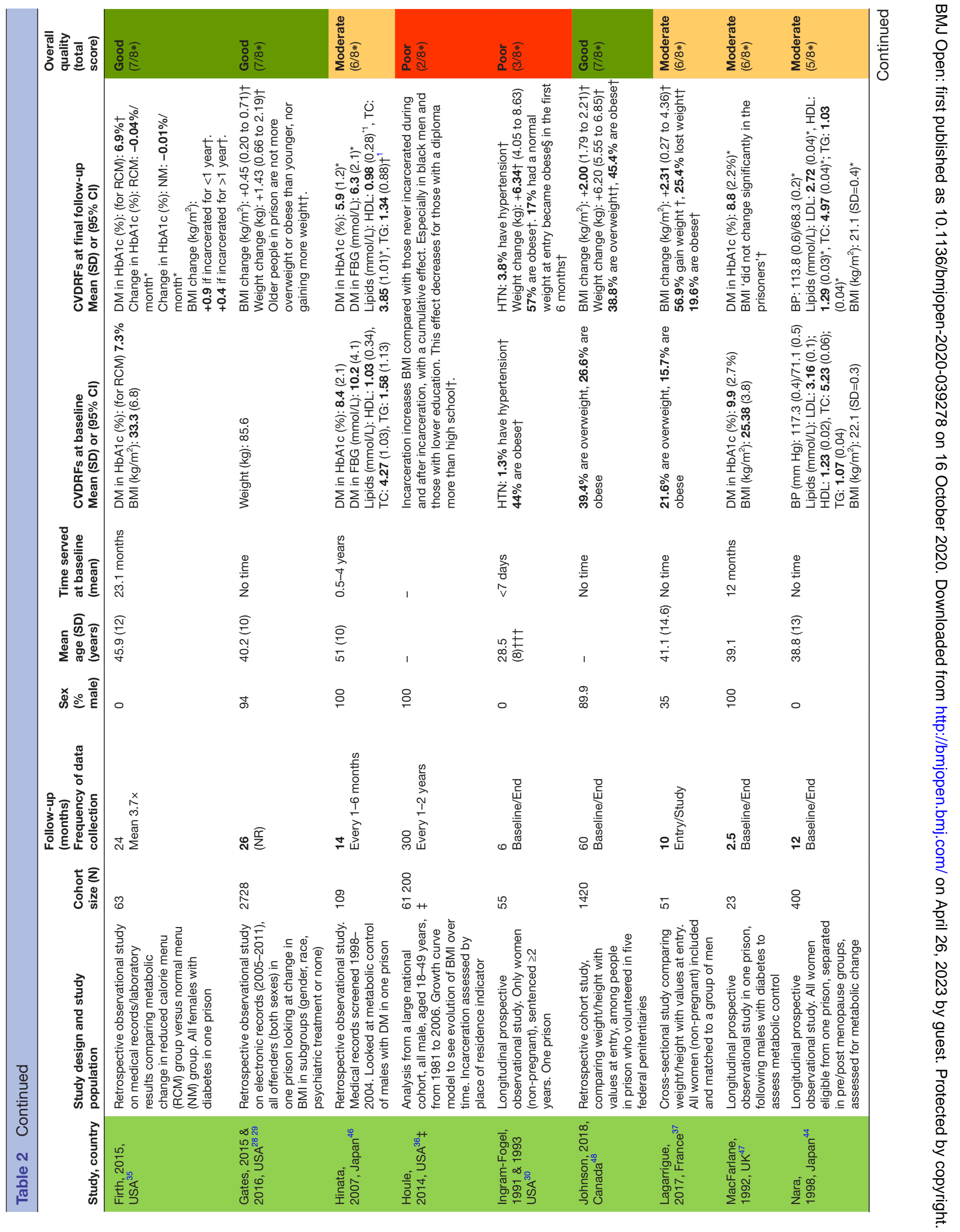




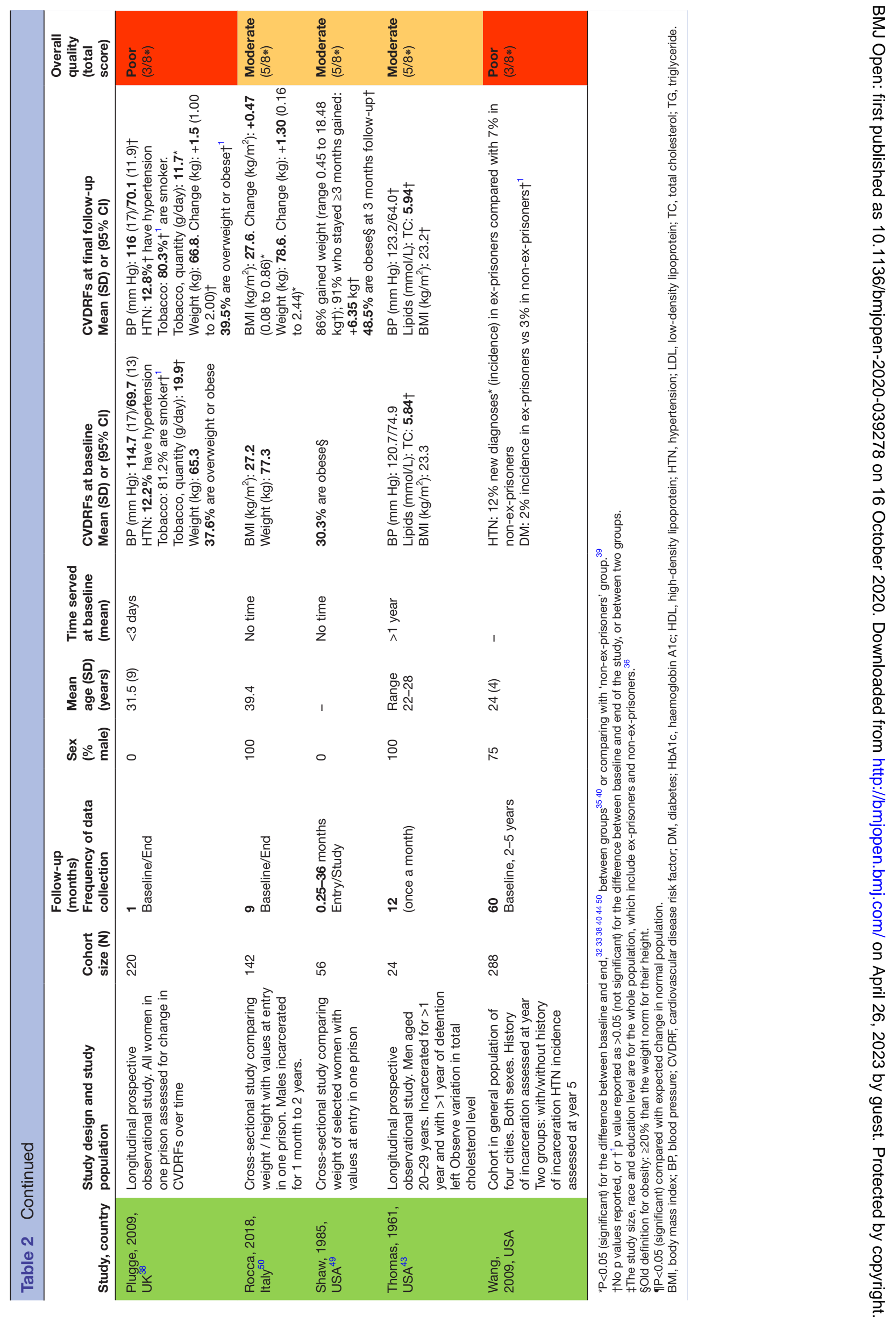




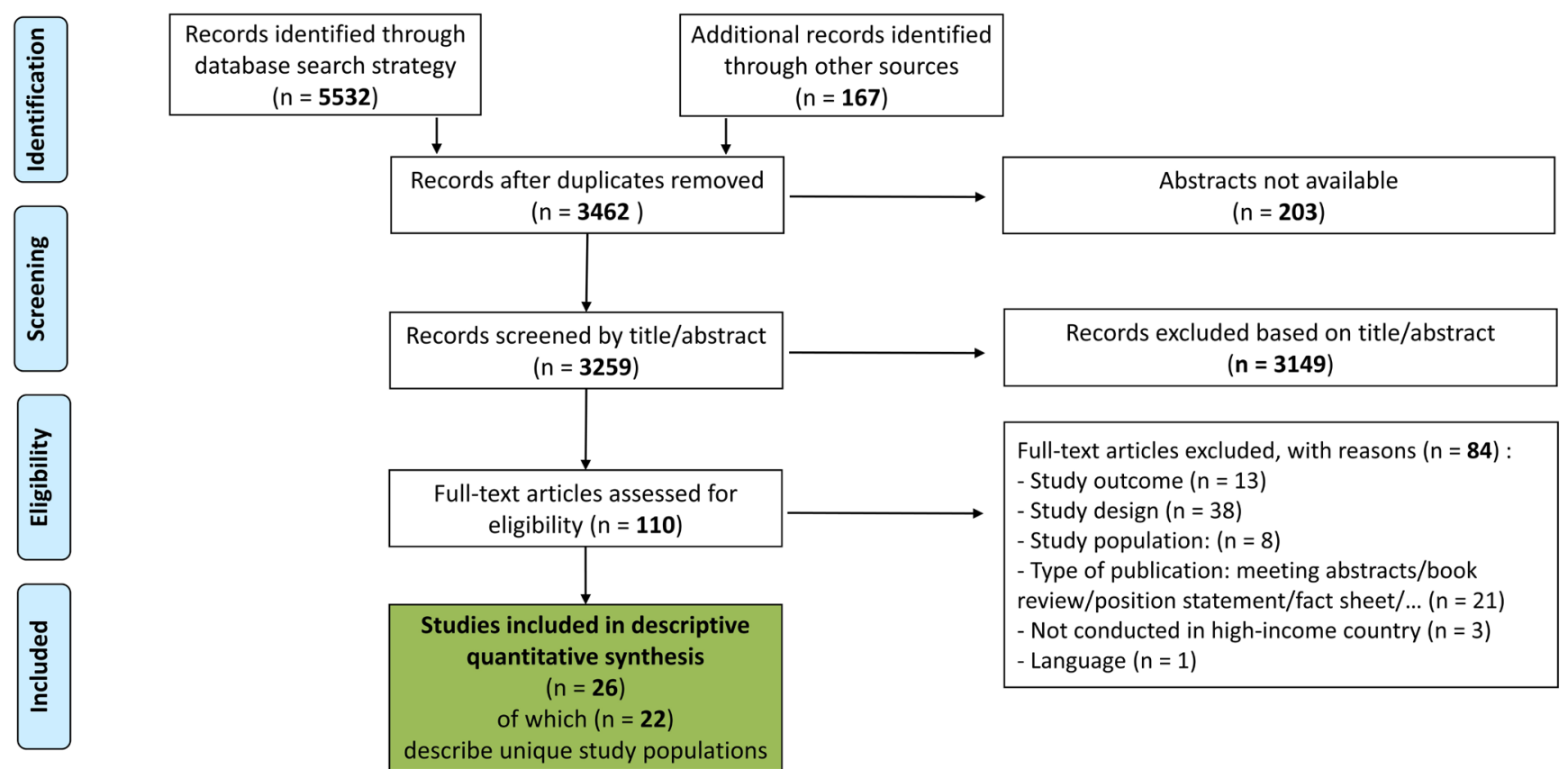

Figure 1 Preferred Reporting Items for Systematic Reviews and Meta-Analyses flow chart.

the control of one's diabetes, reflected by a decrease in haemoglobin A1c (HbA1c) ${ }^{35} 4647^{*}$ and reduced fasting blood glucose $(\mathrm{FBG}){ }^{46^{*}}$ Interestingly, one study from Japan $^{46^{*}}$ showed a significant decrease in mean HbA1c from $8.4 \%$ to $5.9 \%$ over 14 months. To explore the link between food served and the control of one's diabetes, Firth et al compared people in prison receiving a new reduced calorie menu (RCM) implemented by the prison administration (ie, not a research intervention) offering $2200 \mathrm{kcal} /$ day to those still receiving the normal menu (NM) with $3000 \mathrm{kcal} /$ day. ${ }^{35}$ Improvements in mean HbA1c were reported in both groups, but the decrease was significantly more marked in the RCM group compared with the NM group. Davoust et at5 found a statistically non-significant rise of $0.26 \%$ in HbAlc during the 3 months of follow-up in a cohort of 15 people. Lastly, one paper found that ex-prisoners were not at higher risk of developing DM after incarceration than those who had never been incarcerated. ${ }^{39}$

\section{Tobacco use}

Five articles ${ }^{25-273841}$ describing three original studies ${ }^{25} 3841$ (one in which tobacco use was prohibited in the study setting $^{41}$ ) addressed trends in tobacco use during and following incarceration. In prisons without a smoking ban, the incidence of smoking did not change significantly between baseline and follow-up, which ranged from 1 to 6 months. ${ }^{25} 38$ One study reported a significant decrease in the quantity of tobacco smoked 1 month after entering prison (from $19.9 \mathrm{~g}$ to $11.7 \mathrm{~g} /$ day). ${ }^{38^{*}}$ In the study by Cropsey et al, ${ }^{25}$ the fact that $2.8 \%$ of the smokers quit was counterbalanced by the fact that another $14.2 \%$ self-reporting that they started smoking for the first time in prison. ${ }^{25}$ Moreover, in another study, it was found that $50.8 \%$ of smokers increased their consumption after entering prison compared with $15.8 \%$ who decreased their consumption. ${ }^{25}$ The self-reported increase in tobacco consumption during incarceration was especially marked among African-American smokers in one allfemale cohort. ${ }^{27}$ Finally, one study found that that $92.8 \%$ of smokers had relapsed at 3 weeks following release ${ }^{41}$ from a tobacco-free prison.

\section{Dyslipidaemia}

Four articles addressed the association between dyslipidaemia and incarceration with conflicting findings. ${ }^{3243446}$ Two reported an increase in total cholesterol (TC), low-density lipoprotein (LDL) and triglycerides (TG) levels ${ }^{32} 43$ and a decrease in high-density lipoprotein (HDL) during incarceration. ${ }^{32}$ However, these changes either did not reach statistical significance or the level of statistical significance was not reported. In contrast, both Japanese papers on this topic found a statistically significant decrease in TC during incarceration. ${ }^{44} 46^{*}$

\section{Physical inactivity and unhealthy diet}

One study by Plugge $e t a l^{8}$ addressed the association between physical activity, diet and incarceration in a cohort of 220 women in prison in the UK. What they found was a low level of physical activity at entry into prison and no significant change at a 1 month follow-up. They also found a statistically non-significant decrease in women following the recommended healthy diet each day from $13.4 \%$ to $8.3 \%$ during the same time period. 


\section{Weight and obesity}

Eighteen studies addressed the association between weight and incarceration. ${ }^{29-384048-50}$ Thirteen $^{31333738404849}$ reported either a positive change in the prevalence of people in prison being overweight and obese or an increase of weight or BMI during or after incarceration. ${ }^{29-38} 4048-50$ The identified risk factors for weight gain during incarceration in the reviewed studies included being a black man, ${ }^{36}$ being a woman ${ }^{25} 3437$ (especially women who quit smoking during incarceration ${ }^{26}$ ) and taking antidepressants or antipsychotics. ${ }^{29}$

Five studies report a decrease in BMI or weight in relation to incarceration: one Japanese study ${ }^{4} *$ found a change in BMI of $-1.0 \mathrm{~kg} / \mathrm{m}^{2}$ over $12-14$ months of incarceration, two found trends towards decreased weight ${ }^{25}$ of $-1.86 \mathrm{~kg}$ and $\mathrm{BMI}^{43}$ of $-0.1 \mathrm{~kg} / \mathrm{m}^{2}$ that did not meet statistical significance, and two reported 'little change" ${ }^{42}$ or 'no significant change in BMI' ${ }^{47}$ without providing quantitative data.

\section{Meta-regression}

To summarise findings related to changes in weight and BMI from baseline to follow-up, study effect sizes were graphed on a forest plot in order of increasing length of follow-up. There were marked differences in follow-up time between studies, ranging from 0.5 to 60 months. Consequently, no overall summary index could be computed at this stage. Despite this limitation, the forest plots (figures 2 and 3) illustrate that the majority of results lie on the positive side (ie, side of increase) in both the change in weight and change in BMI. In a second stage, in order to assess the overall change in weight and BMI over time, we carried out a meta-regression on the change in weight (figure 4) and BMI (figure 5) during incarceration. Five studies 3235434449 could not be included in the computation as they lacked necessary data (ie, unavailable SEs) and we were unable to reach the authors to gather the required data. These studies were represented by a simple dot on the plots as shown in figures 2 and 3 . It was found that the mean weight gain during incarceration was $0.30 \mathrm{~kg}(95 \% \mathrm{CI}-0.03$ to 0.6$)$ at 1 month, 3.1 $\mathrm{kg}(95 \%$ CI -0.01 to 6.3$)$ at 1 year and $5.3 \mathrm{~kg}(95 \%$ CI 0.5 to 10.1 ) at 2 years. The mean increase in BMI was $1.1 \mathrm{~kg} /$ $\mathrm{m}^{2}(95 \% \mathrm{CI}-0.7$ to 2.9$)$ at 1 year and $1.8 \mathrm{~kg} / \mathrm{m}^{2}(95 \% \mathrm{CI}$ -0.9 to 4.6$)$ after 2 years of incarceration. The $\tau^{2}$ was 10.3 for the change in weight and 1.7 for the change in BMI.

\section{DISCUSSION}

The results of this study showed that the mean weight or BMI of the people in prison in high-incomes countries seemed to increase during incarceration. This effect appears most pronounced in the first 2 years of

\section{Weight change}

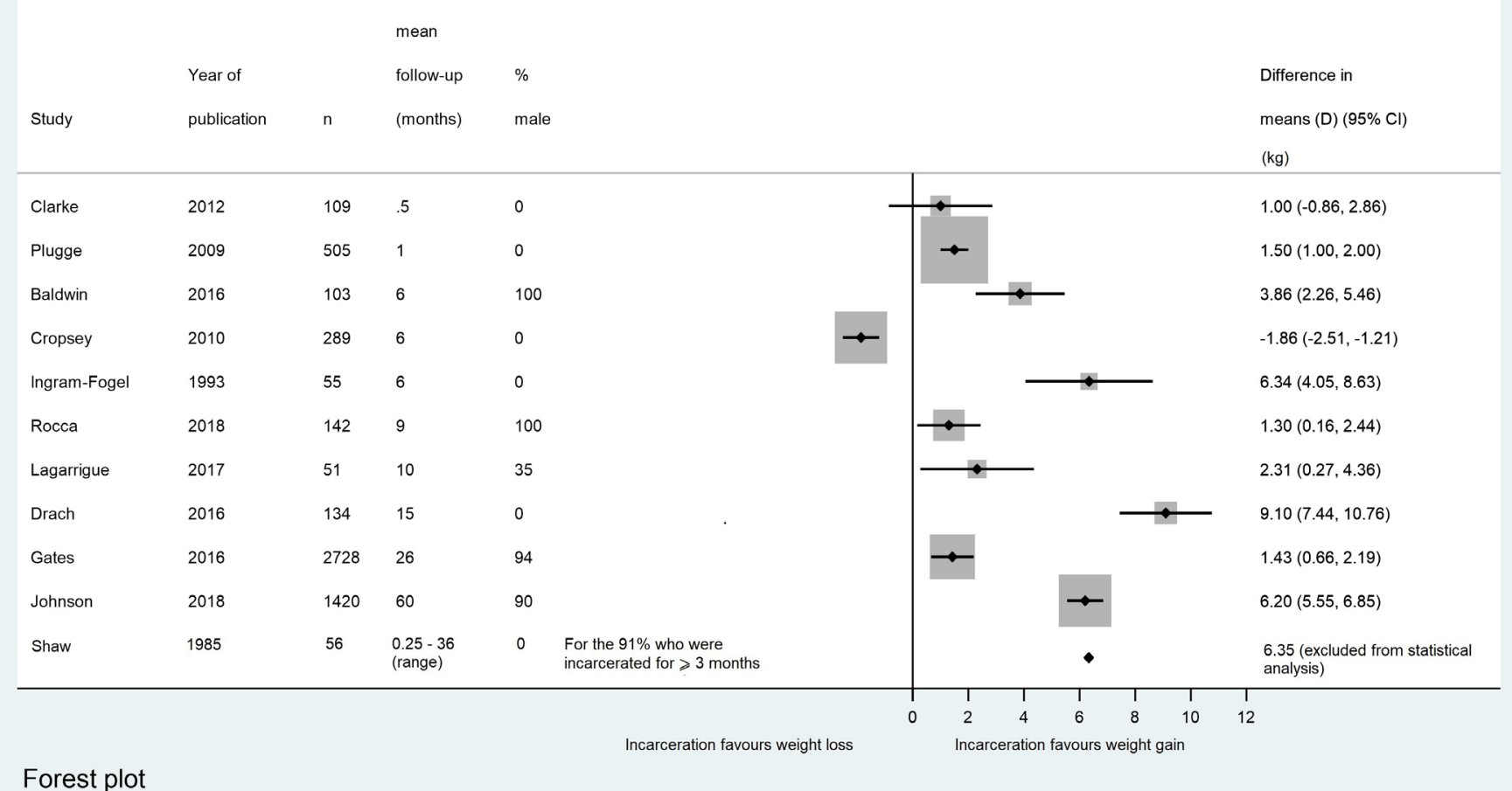

Figure 2 Weight change during incarceration (forest plot). The follow-up periods between studies ranged from 0.5 to 60 months. Due to the presence of strong heterogeneity and the fact that there is a dose-response relation of the outcomes with time, we were unable to depict combined findings in this forest plot. Instead, a meta-regression analysis was conducted (figure 4). 


\section{BMI change}

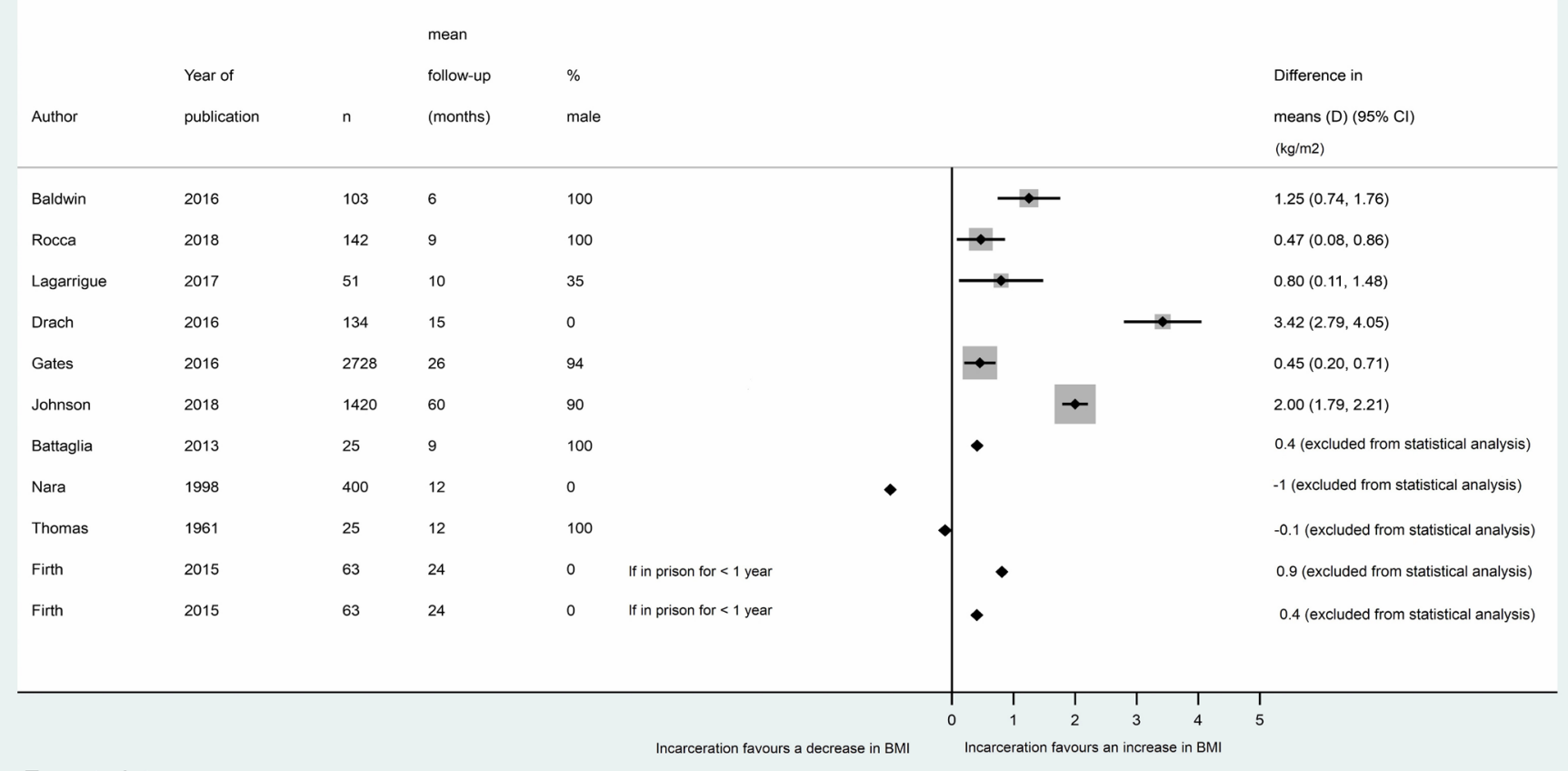

Forest plot

Figure 3 Body mass index (BMI) change during incarceration (forest plot). The follow-up periods between studies ranged from 6 to 60 months. Due to the presence of strong heterogeneity and the fact that there is a dose-response relation of the outcomes with time, we were unable to depict combined findings in this forest plot. Instead, a meta-regression analysis was conducted (figure 5).

incarceration and levels off beyond 2 years. Of the seven studies that addressed the relationship between incarceration and HTN, six showed a trend towards either an increasing blood pressure or the prevalence of HTN during incarceration, or an increased incidence of HTN following incarceration. However, as the majority of these results were not statistically significant, the relationship between incarceration and the evolution of HTN remains unclear. For all other CVDRFs assessed, the results were contradictory or inconclusive limiting our ability to draw any clear conclusions about the impact of incarceration on the trends in these CVDRFs over time based on the available evidence.

\section{Weight and obesity}

By conducting a meta-regression on available data relating to incarceration and change in weight and BMI over time, an overall rise in weight and BMI during incarceration was found. In figures 4 and 5, a steeper slope in weight and BMI over time (ie, more pronounced change) was seen at the beginning of incarceration, particularly during the first few months, and appeared to level off after 2 years. Compared with the average weight gain of the middleaged US population, estimated to be between 0.5 and 1 $\mathrm{kg} /$ year, $^{51}$ the mean weight gain found in this review was up to five times higher in the first 2 years of imprisonment. Hypothesised reasons for this include a combination of a sedentary lifestyle and a poor diet (the high calorie meals served in prison and the extra snacks or sweet beverages purchased from the commissary store), ${ }^{11} 5253$ forced smoking cessation (which has been associated with weight gain $^{54}$ ), a high prevalence of people in prison taking psychotropic medication (known to affect weight), ${ }^{11}$ high rates of depressive symptoms ${ }^{55}$ and high levels of stress. ${ }^{56}$ Many of these factors are interconnected which might create a vicious cycle of weight gain. For instance, it has been found that depression increases the odds of developing obesity among people in prison, while obesity may increase the risk for depression. ${ }^{57}$ Furthermore, current or recent incarceration is associated with depression and mood disorders, ${ }^{58} 59$ and chronic stress is associated with poor eating behaviours and obesity ${ }^{60}$ However, how and to what extent these diverse factors contribute to weight gain among people in prison remains unclear. To further complicate the issue, a recent systematic review ${ }^{23}$ found that $42 \%-75 \%$ of people in prison gained weight while incarcerated which was thought to be due to importing poor health behaviours from the community into prison, as well as individuals adapting to the prison environment by building muscles to demonstrate strength among peers. As such, the authors of this review highlight that BMI may be a poor marker of weight gain in prison because bodybuilding positively changes the ratio of fatto-muscle mass raising the BMI while potentially reducing cardiovascular risk. However, the extent to which physical 

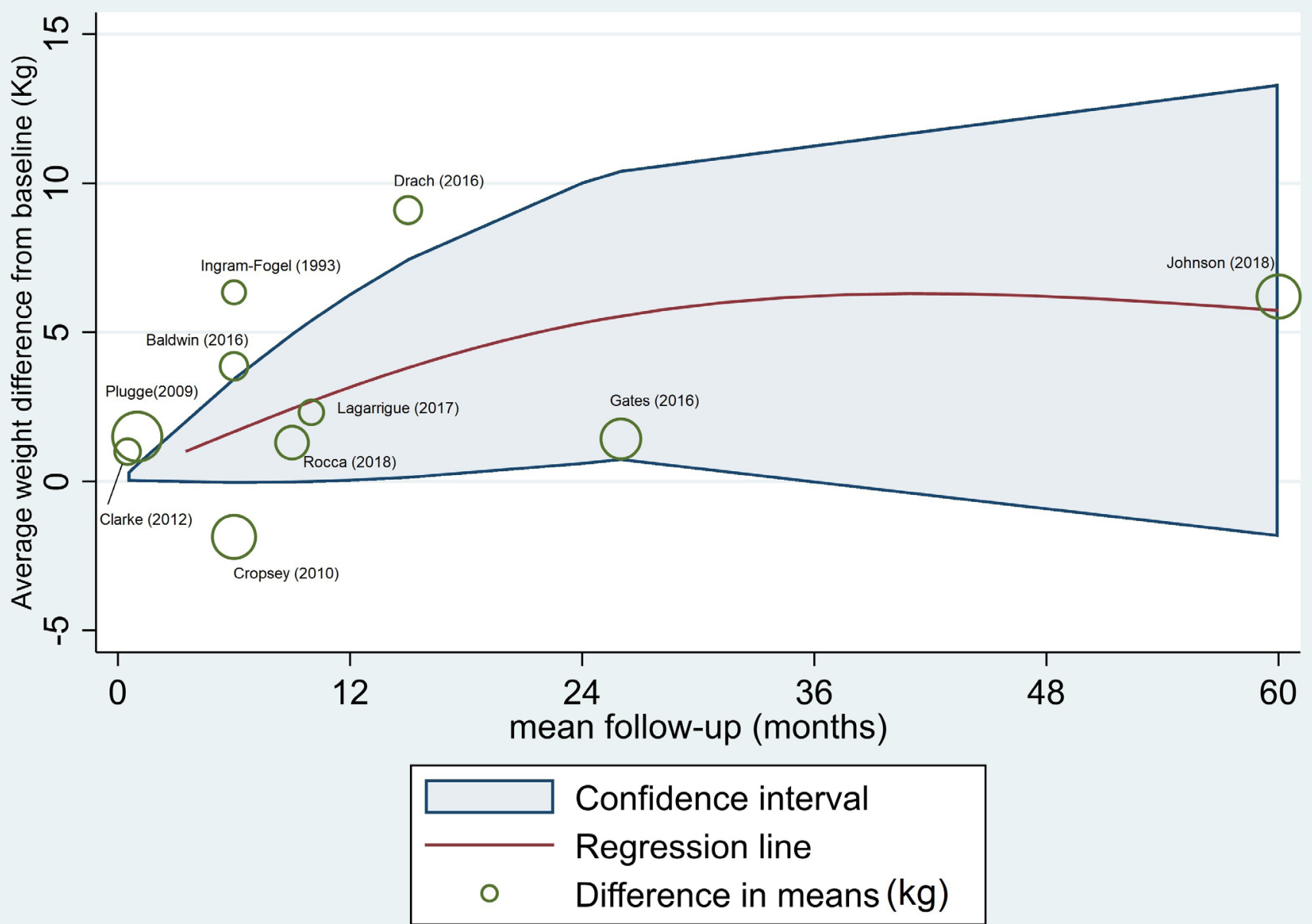

Figure 4 Weight change during incarceration (meta-regression) based on findings of 10 studies.

training can explain the rising prevalence of weight gain in people in prison during incarceration is unknown.

In terms of the long-term impact of incarceration on weight gain, only one study addressed this issue by examining weight gain in a large US-based cohort ( $\mathrm{n}=61200)$ of ex-prisoners with a follow-up of 25 years. The authors concluded that those incarcerated or with a history of incarceration have a higher increase in BMI over time, especially for black people in prison and those with lower education, compared with non-exprisoners. ${ }^{36}$ Nonetheless, the quality of this study was judged poor, and the growth curve models used were hard to interpret in detail.

A meta-analysis ${ }^{61}$ published in 2018 examining a similar question to our current systematic review (ie, association between weight gain and incarceration) reported a positive weight change during incarceration, with a mean increase of $0.43 \mathrm{lbs}(0.19 \mathrm{~kg})$ per week. Implicitly, these authors assumed a linear gain in weight over time. Our results, however, challenge this hypothesis by showing that weight gain may not be linear throughout incarceration but instead may increase steeply during the initial period of incarceration and then plateau over time.

Explanations for the more pronounced weight change noted among women in one of the reviewed ${ }^{28}$ study include a smaller number of facilities and programmes in female prisons leading to fewer recreational activities and a more sedentary lifestyle; meals served containing the same amount of calories as those served to $\operatorname{men}^{18}$ and more antipsychotic medications prescribed to women than men in prisons. ${ }^{62}$ The only study reporting a significant decrease in BMI in this review was conducted in Japan, whose findings were likely due to low calorie diets and food restrictions implemented in Japanese prisons. Further studies are needed to elucidate whether the weight loss seen in this study is due to healthy weight loss or weight loss caused by high-stress prison conditions.

\section{Hypertension}

Among available studies examining the association between HTN and incarceration, all but one showed a trend over time towards either a rise in BP during incarceration, ${ }^{32} 384243$ a higher prevalence of HTN among people in prison ${ }^{30} 38$ or a higher incidence of HTN in people released from prison compared with those never incarcerated. ${ }^{39}$ Few driving factors have been hypothesised to explain this unconfirmed and non-significant trend. Although most findings were statistically nonsignificant, trends towards an increase in BP or in the 

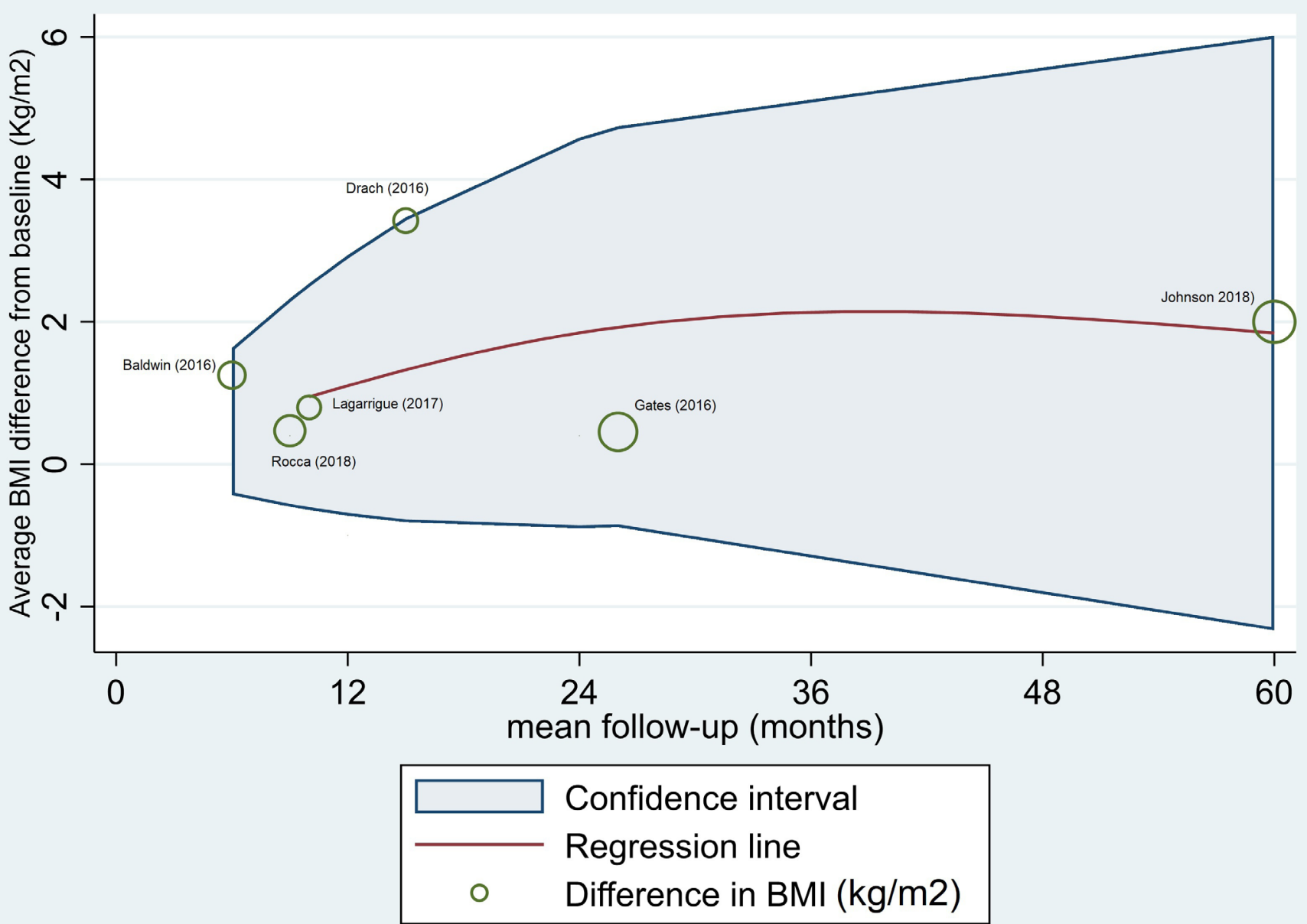

Figure 5 Body mass index (BMI) change during incarceration (meta-regression) based on findings of six studies.

prevalence of HTN during incarceration seems highly plausible due to a number of factors discussed throughout the reviewed studies. First, prison crowding, ${ }^{42}$ whereby people in prison are confined to a limited space and exposed to high noise stress, with an increased number of threatening interactions with other prisoners and guards. Second, incarceration conditions are inherently stressful, and the link between psychosocial stress and HTN is well established. ${ }^{63}$ Third, the sedentary lifestyle of people in prison may contribute to weight gain, which is also associated with an increase in $\mathrm{BP} .{ }^{64}$ Finally, despite institutional efforts made in many prisons to reduce dietary sodium, ${ }^{65}$ high salt diets are often still served. ${ }^{38} 66$ Interestingly, working ${ }^{42}{ }^{44}$ appears to be a protective factor against HTN during incarceration. The causes for this association are not clear but it is plausible that work might contribute to a more active lifestyle or help reduce stress levels during incarceration. The explanation for the significant decrease in BP reported by Nara and Igarashi ${ }^{44}$ could be related to the specific prison environment, which is described in the two Japanese articles included in this review. ${ }^{44}$ The very strict detention conditions include a smoking ban, calorie restriction for all $(1800 \mathrm{kcal} /$ day for women and $2500 \mathrm{kcal} /$ day for men), prohibition to eat between meals and at night and a ban on extra food like snacks or sweetened drinks. Finally, the persisting effect of incarceration on HTN after release found in one study ${ }^{39 *}$ might be explained by psychosocial factors due to the ongoing stress caused by adaptations required to life outside prison, including a limited access to employment and changes in social relationships for ex-prisoners. Further research is needed into the causal factors behind this association between HTN and incarceration, well beyond the time of incarceration.

\section{Diabetes}

Three of the four studies that looked at changes in blood sugar control during incarceration point to better blood sugar control during incarceration. However, of these three studies, ${ }^{35} 4647$ one was conducted in Japan in a prison setting with calorie restriction for all prisoners, ${ }^{46}$ and one ${ }^{35}$ showed the most pronounced effect in those receiving a RCM $(2200 \mathrm{kcal} /$ day $)$. For both studies, the main driver of improved blood sugar control may have been be the calorie reduction instead of incarceration itself. Other explanations could be that some aspects of prison life contribute to improved blood sugar control such as the provision of regular meals and daily access 
to the prison yard and scheduled sports, providing more opportunities for better eating and physical activity than prior to incarceration. It should also be considered that some individuals may have had limited access to healthcare prior to incarceration which may have adversely impacted their diabetes control. ${ }^{18} 67$ Finally, despite a higher odd of DM seen among people in prison, ${ }^{12}$ only one study identified in this review looked at the association between incarceration and the incidence of DM in people released from prison compared with those never incarcerated, in which no significant association was found. ${ }^{39}$

\section{Tobacco use}

The prevalence of smoking among people in prison is very high. ${ }^{19-22}$ Surprisingly, very few longitudinal studies were identified that assessed the change in smoking habits during incarceration that did not involve the evaluation of a smoking cessation intervention. The only study identified in this review that addressed this question was by Plugge $e t a l,{ }^{38}$ who reported a decrease in the quantity of tobacco consumed during incarceration. However, the follow-up was only 1 month, and started right after entering prison, which raises the question of the accessibility of tobacco in the first days to weeks of incarceration. Overall, further studies are needed to better understand the impact of incarceration on tobacco use. The public health response to the high prevalence of smoking in prisons in some countries has been to implement smoking bans, including in many states across the USA ${ }^{68}$ as well as in Japan. However, rules vary considerably by country and region, ${ }^{69}$ as smoking bans were not reported in the French, ${ }^{3745}$ Italian $^{32} 50$ and English ${ }^{38} 47$ prisons described in the included studies. Although smoking bans appeared to be beneficial in reducing the health impacts of tobacco use, such as in-prison mortality, ${ }^{70}$ the impact that smoking bans have on long-term tobacco use is inconsistent in the current literature. One study ${ }^{71}$ showed that a majority (76\%) of men in prison continued to smoke 1 month after the implementation of a smoking ban. Moreover, resumption after release from a smoke-free prison appears to be very high in the few studies reporting on this topic. ${ }^{41} 7072-75$ For instance, according to one systematic review, ${ }^{76}>60 \%$ of former smokers relapsed on the first day after release, and almost all resumed smoking within 6 months of release. Despite this high rate of relapse another systematic review, ${ }^{77}$ based on many of the same studies, commented that the rate of relapse varied too much to draw any clear conclusions. Finally, another review ${ }^{22}$ found a similar efficacy of counselling and behavioural interventions aimed at smoking cessation in a prison setting when compared with a community setting, thus highlighting the potential benefits of pharmacological and psychological interventions in prisons to reduce high tobacco consumption and supporting sustained smoking cessation.
Dyslipidaemia, physical inactivity and unhealthy diet

A previous systematic review highlighted that the food served in prison settings was atherogenic, lacking in fruits and vegetables and with high saturated fat and sodium content above the recommended limits. ${ }^{11}$ However, due to limited findings regarding trends over time of dyslipidaemia, physical inactivity and unhealthy diet in relation to incarceration identified in this review, no conclusions could be drawn. Further research in this area is required.

\section{Strengths and limitations}

Some limitations of this systematic review require consideration. First, there is a high degree of uncertainty in the estimates of the meta-regression curve produced in the analysis. This is due to the small number of included studies and the substantial residual betweenstudy variances as reflected by the large CIs. In addition, we found substantial heterogeneity between studies, which may be attributable to differences in incarceration conditions that were not accounted for within individual studies. Moreover, differences in prison contexts and population characteristics may have also influenced changes seen in CVDRFs during incarceration such as: smoking bans, the prison security level, access to regular physical activity, the type and quantity of food served and purchased, access to and frequency of work and whether those studied were facing incarceration for the first time or had been exposed to multiple periods of incarceration. Only studies from high-income countries were included, thus limiting the generalisability of our results to low-income or middle-income countries. Lastly, the literature search was conducted in December 2018, and more recent publications could change some of our findings. We were unable to conduct an updated search prior to publication.

The main strength of this review is that our statistical approach (a random-effects meta-regression model) allowed us to assess the dose-response relationship between time spent in prison and changes in weight and BMI over time. This methodology might help shift the focus in this area of research to improve our understanding of the temporal relationship between weight gain and incarceration and identify key mediating factors.

\section{CONCLUSION AND RECOMMENDATIONS}

This review reinforces previous results of a positive association between weight gain and incarceration but newly highlights that this effect may be most pronounced during the first 2 years of incarceration. These findings could allow us to think about incarceration like an aggregate adverse determinant of health serving as an important part of our clinical history taking (ie, whether someone has been previously incarcerated or not) when assessing individual cardiovascular risk. Concerning HTN, the results were inconclusive, despite 
a trend towards either a rise in blood pressure or a raising prevalence of HTN during incarceration, and in one study a higher incidence of HTN among ex-prisoners compared with non-ex-prisoners. More studies are needed to confirm or overrule this tendency.

Since this review only focused on studies conducted in high-income countries, further research should be encouraged on a global scale to improve our understanding of the relationship between incarceration and CVDRFs over time. Despite prior reviews reporting a higher prevalence of most other CVDRFs including smoking, dyslipidaemia, unhealthy diet and physical inactivity, we could not conclude whether there was a positive (or negative) trend over time during or after incarceration given the current available literature. More studies are needed to fill this gap.

Primary prevention and treatment of noncommunicable diseases including CVD in prison have largely been neglected. ${ }^{21}$ The prison setting offers unique opportunities for the prevention and management of CVDRFs, as its milieu is controlled in terms of daily physical activity or work, caloric intake, tobacco availability and access to healthcare. The Japanese prison environment proved to be very efficient at controlling or improving diabetes, HTN and BMI, however such conditions might not be appropriate for all countries or cultures and may have other deleterious effects that have not yet been explored (ie, excessive weight loss, increased stress or depressive mood) in comparison to less strict prison environments. Interventions involving structured physical activity, diet modification, nutrition education and smoking cessation can improve the cardiovascular health of people in prison while incarcerated. ${ }^{19}$ Additional efforts should be made to support those taking antipsychotic or antidepressant drugs in order to avoid worsening CVDRFs through associated weight gain and dyslipidaemia. Furthermore, due to possible beneficial effects on CVDRFs, we would recommend that people in prison have access to work that facilitates regular physical activity in order to tackle the inactivity and psychosocial stress inherent to the prison environment. Future studies should focus on the mediating factors in the relationship between incarceration and major CVDRFs.

Finally, due to the ubiquity of bodybuilding in prisons, studies in this area should consider reporting waist circumference, which may be a better marker of weight gain or obesity than BMI or weight gain in the prison context. ${ }^{23}$

\footnotetext{
Author affiliations

${ }^{1}$ Department of Vulnerable Populations and Social Medicine, Center for Primary Care and Public Health (Unisanté), Lausanne, Vaud, Switzerland

${ }^{2}$ Division of Biostatistics, Center for Primary Care and Public Health (Unisanté), Lausanne, Vaud, Switzerland

${ }^{3}$ Department of Ambulatory Care and Community Medicine, Center for Primary Care and Public Health (Unisanté), Lausanne, Vaud, Switzerland

${ }^{4}$ Medical Library, CHUV, Lausanne, Vaud, Switzerland

${ }^{5}$ Medicine, University of Calgary Cumming School of Medicine, Calgary, Alberta, Canada
}

Contributors $\mathrm{CB}$ and PB conceived and designed the study. CB and CJ designed the search strategy, $\mathrm{CC}$ provided important input regarding review methodology. $\mathrm{CB}$ and $A A$ reviewed the articles and extracted the data, with the assistance of $P B$ and CC. PT did the statistical analysis. CB and PB interpreted the data. CB drafted the article. MM assisted with data interpretation and critically revised the manuscript for important intellectual content. All authors reviewed and provided constructive feedback and approve of the final submitted version.

Funding The authors have not declared a specific grant for this research from any funding agency in the public, commercial or not-for-profit sectors.

Competing interests None declared.

Patient and public involvement Patients and/or the public were not involved in the design, or conduct, or reporting, or dissemination plans of this research.

Patient consent for publication Not required.

Provenance and peer review Not commissioned; externally peer reviewed.

Data availability statement Data sharing not applicable as no datasets generated and/or analysed for this study. All data relevant to the study are included in the article or uploaded as supplementary information. Given our manuscript is a systematic review of the literature, all data used in our analysis are available in the published literature.

Open access This is an open access article distributed in accordance with the Creative Commons Attribution Non Commercial (CC BY-NC 4.0) license, which permits others to distribute, remix, adapt, build upon this work non-commercially, and license their derivative works on different terms, provided the original work is properly cited, appropriate credit is given, any changes made indicated, and the use is non-commercial. See: http://creativecommons.org/licenses/by-nc/4.0/.

\section{ORCID iDs}

Constantin Bondolfi http://orcid.org/0000-0003-1900-360X

Carole Clair http://orcid.org/0000-0001-5281-0943

\section{REFERENCES}

1 WHO. Cardiovascular diseases (CVDs) fact sheet, 2016. Available: http://www.who.int/mediacentre/factsheets/fs317/en/

2 Roth GA, Johnson C, Abajobir A, et al. Global, regional, and national burden of cardiovascular diseases for 10 causes, 1990 to 2015. J Am Coll Cardiol 2017;70:1-25

3 Wang EA, Redmond N, Dennison Himmelfarb CR, et al. Cardiovascular Disease in Incarcerated Populations. J Am Coll Cardiol 2017;69:2967-76.

4 Research. IfCP. World prison brief, 2018. Available: http://www. prisonstudies.org/

5 Wakefield S, Uggen C. Incarceration and stratification. Annu Rev Sociol 2010;36:387-406.

6 Skarupski KA, Gross A, Schrack JA, et al. The health of America's aging prison population. Epidemiol Rev 2018;40:157-65.

7 Hayes AJ, Burns A, Turnbull P, et al. The health and social needs of older male prisoners. Int J Geriatr Psychiatry 2012;27:1155-62.

8 Lars Møller HS, AGaHN RJ. Health in prisons. A WHO guide to the essentials in prison health 2007.

9 CDC. Correctional health - Scientific Reports \& MMWRs. Available: https://www.cdc.gov/correctionalhealth

10 Novick LF, Penna RD, Schwartz MS, et al. Health status of the new York City prison population. Med Care 1977;15:205-16.

11 Agyapong NAF, Annan RA, Apprey C. Prevalence of risk factors of cardiovascular diseases among prisoners: a systematic review. Nutr Food Sci 2017;47:896-906.

12 Arries EJ, Maposa S. Cardiovascular risk factors among prisoners: an integrative review. J Forensic Nurs 2013;9:52-64.

13 Binswanger IA, Merrill JO, Krueger PM, et al. Gender differences in chronic medical, psychiatric, and substance-dependence disorders among jail inmates. Am J Public Health 2010;100:476-82.

14 Fickenscher A, Lapidus J, Silk-Walker P, et al. Women behind bars: health needs of inmates in a County jail. Public Health Rep 2001;116:191-6.

15 Harzke AJ, Baillargeon JG, Pruitt SL, et al. Prevalence of chronic medical conditions among inmates in the Texas prison system. $J$ Urban Health 2010;87:486-503.

16 Binswanger IA, Krueger PM, Steiner JF. Prevalence of chronic medical conditions among jail and prison inmates in the USA compared with the general population. J Epidemiol Community Health 2009;63:912-9. 
17 D'Souza RM, Butler T, Petrovsky N. Assessment of cardiovascular disease risk factors and diabetes mellitus in Australian prisons: is the prisoner population unhealthier than the rest of the Australian population? Aust N Z J Public Health 2005;29:318-23.

18 Herbert K, Plugge E, Foster C, et al. Prevalence of risk factors for non-communicable diseases in prison populations worldwide: a systematic review. Lancet 2012;379:1975-82.

19 Mohan ARM, Thomson P, Leslie SJ, et al. A systematic review of interventions to improve health factors or behaviors of the cardiovascular health of prisoners during incarceration. J Cardiovasc Nurs 2018;33:72-81.

20 Richmond RL, Butler T, Belcher JM, et al. Promoting smoking cessation among prisoners: feasibility of a multi-component intervention. Aust N Z J Public Health 2006;30:474-8.

21 Plugge E, Martin R, Hayton P. Noncommunicable diseases and prisoners. in: prisons and health, who regional office for Europe. Copenhagen 2014

22 Spaulding AC, Eldridge GD, Chico CE, et al. Smoking in correctional settings worldwide: prevalence, bans, and interventions. Epidemiol Rev 2018:40:82-95 https://dx.doi.org/

23 Choudhry K, Armstrong D, Dregan A. Systematic review into obesity and weight gain within male prisons. Obes Res Clin Pract 2018:12:327-35.

24 Wells BS, O'Connell JP, Welch V, et al. The Newcastle-Ottawa scale (NOS) for assessing the quality of nonrandomised studies in metaanalyses. Available: www.ohri.ca/programs/clinical_epidemiology/ oxford.asp

25 Cropsey K, Eldridge G, Weaver M, et al. Smoking cessation intervention for female prisoners: addressing an urgent public health need. Am J Public Health 2008;98:1894-901.

26 Cropsey KL, McClure LA, Jackson DO, et al. The impact of quitting smoking on weight among women prisoners participating in a smoking cessation intervention. Am J Public Health 2010;100:1442-8.

27 Cropsey KL, Weaver MF, Eldridge GD, et al. Differential success rates in racial groups: results of a clinical trial of smoking cessation among female prisoners. Nicotine Tob Res 2009;11:690-7.

28 Gates ML, Bradford RK. The impact of incarceration on obesity: are prisoners with chronic diseases becoming overweight and obese during their confinement? J Obes 2015;2015:1-7.

29 Gates ML, Wilkins T, Ferguson E, et al. Gender and race disparities in weight gain among offenders prescribed antidepressant and antipsychotic medications. Health Justice 2016;4:6.

30 Ingram-Fogel Cl. Hard time: the stressful nature of incarceration for women. Issues Ment Health Nurs 1993;14:367-77.

31 Ingram-Fogel C. Health problems and needs of incarcerated women. Journal of Prison and Jail Health 1991;10:43-57.

32 Battaglia C, di Cagno A, Fiorilli G, et al. Benefits of selected physical exercise programs in detention: a randomized controlled study. Int $J$ Environ Res Public Health 2013;10:5683-96.

33 Baldwin N, Clarke JG, Roberts MB. Weight change during incarceration: Groundwork for a collaborative health intervention. $J$ Health Care Poor Underserved 2016;27:1567-76.

34 Drach LL, Maher JE, Braun MJF, et al. Substance use, disordered eating, and weight gain: describing the prevention and treatment needs of incarcerated women. $J$ Correct Health Care 2016;22:139-45.

35 Firth CL, Sazie E, Hedberg K, et al. Female inmates with diabetes: results from changes in a prison food environment. Womens Health Issues 2015;25:732-8.

36 Houle B. The effect of incarceration on adult male BMI trajectories, United States, 1981-2006. J Racial Ethn Health Disparities 2014;1:21-8.

37 Lagarrigue A, Ajana S, Capuron L, et al. Obesity in French inmates: gender differences and relationship with mood, eating behavior and physical activity. PLoS One 2017;12:e0170413.

38 Plugge EH, Foster CE, Yudkin PL, et al. Cardiovascular disease risk factors and women prisoners in the UK: the impact of imprisonment. Health Promot Int 2009;24:334-43.

39 Wang EA, Pletcher M, Lin F, et al. Incarceration, incident hypertension, and access to health care: findings from the coronary artery risk development in young adults (cardia) study. Arch Intern Med 2009;169:687-93.

40 Clarke JG, Waring ME. Overweight, obesity, and weight change among incarcerated women. J Correct Health Care 2012;18:285-92.

41 Clarke JG, Stein LAR, Martin RA, et al. Forced smoking abstinence: not enough for smoking cessation. JAMA Intern Med 2013;173:789-94.

42 D'Atri DA, Fitzgerald EF, Kasl SV, et al. Crowding in prison: the relationship between changes in housing mode and blood pressure. Psychosom Med 1981;43:95-105.
43 Thomas CB, Holljes HW, Eisenberg FF. Observations on seasonal variations in total serum cholesterol level among healthy young prisoners. Ann Intern Med 1961;54:413.

44 Nara K, Igarashi M. Relationship of prison life style to blood pressure, serum lipids and obesity in women prisoners in Japan. Ind Health 1998;36:1-7

45 Davoust S, Ghaleb V, Guillon S, et al. The impact of medicationfocused workshops in a diabetes educational program in jail: a pilot study. Int J Clin Pharm 2016;38:203-7.

46 Hinata M, Ono M, Midorikawa S, et al. Metabolic improvement of male prisoners with type 2 diabetes in Fukushima prison, Japan. Diabetes Res Clin Pract 2007;77:327-32.

47 MacFarlane IA, Gill GV, Masson E, et al. Diabetes in prison: can good diabetic care be achieved? BMJ 1992;304:152-5.

48 Johnson C, Chaput J-P, Diasparra M, et al. Canadian federal penitentiaries as obesogenic environments: a retrospective cohort study. CMAJ Open 2018;6:E347-52.

49 Shaw NS, Rutherdale M, Kenny J. Eating more and enjoying it less: U.S. prison diets for women. Women Health 1985;10:39-57.

50 Rocca D. Prevalence of overweight and obesity in an Italian prison and relation with average term of detention: a pilot study. Annali di Igiene 2018;20:51-6 https://dx.doi.org/

51 Hutfless SMN, Wilson RF. Strategies to prevent weight gain among adults. (comparative effectiveness reviews, no. 97.) Introduction. Rockville (MD): Agency for Healthcare Research and Quality (US), 2013. https://www.ncbi.nlm.nih.gov/books/NBK133207/

52 Fazel S, Baillargeon J. The health of prisoners. Lancet 2011:377:956-65.

53 Cashin A, Potter E, Stevens W, et al. Fit for prison: special population health and fitness programme evaluation. Int $J$ Prison Health 2008:4:208-16.

54 Chiolero A, Faeh D, Paccaud F, et al. Consequences of smoking for body weight, body fat distribution, and insulin resistance. Am J Clin Nutr 2008;87:801-9.

55 Block JP, He Y, Zaslavsky AM, et al. Psychosocial stress and change in weight among US adults. Am J Epidemiol 2009;170:181-92.

56 Massoglia M. Incarceration as exposure: the prison, infectious disease, and other stress-related illnesses. J Health Soc Behav 2008;49:56-71.

57 Luppino FS, de Wit LM, Bouvy PF, et al. Overweight, obesity, and depression: a systematic review and meta-analysis of longitudinal studies. Arch Gen Psychiatry 2010;67:220-9.

58 Turney K, Wildeman C, Schnittker J. As fathers and felons: explaining the effects of current and recent incarceration on major depression. $J$ Health Soc Behav 2012;53:465-81.

59 Schnittker J, Massoglia M, Uggen C. Out and down: incarceration and psychiatric disorders. J Health Soc Behav 2012;53:448-64.

60 Torres SJ, Nowson CA. Relationship between stress, eating behavior, and obesity. Nutrition 2007;23:887-94.

61 Gebremariam MK, Nianogo RA, Arah OA. Weight gain during incarceration: systematic review and meta-analysis. Obes Rev 2018:19:98-110.

62 Hassan L, Senior J, Webb RT, et al. Prevalence and appropriateness of psychotropic medication prescribing in a nationally representative cross-sectional survey of male and female prisoners in England. BMC Psychiatry 2016;16:346.

63 Liu M-Y, Li N, Li WA, et al. Association between psychosocial stress and hypertension: a systematic review and meta-analysis. Neurol Res 2017;39:573-80.

64 Beunza JJ, Martínez-González MA, Ebrahim S, et al. Sedentary behaviors and the risk of incident hypertension: the sun cohort. Am J Hypertens 2007;20:1156-62.

65 CDC TR, J.D. Sodium reduction in institutional settings: summary of related laws and policies 2012.

66 Washington PV. Correcting Food Policy in Washington Prisons: How the DOC Makes Healthy Food Choices Impossible for Incarcerated People \& What Can Be Done, 2016. Available: http://prisonvoicewa. org/content/CorrectingFoodPolicy-2016-10-25.pdf

67 Ginn S. Prison environment and health. BMJ 2012;345:e5921

68 Foundation AANR. 100\% Smokefree and Tobacco-Free Correctional Facilities, 2019. Available: http://no-smoke.org/wpcontent/uploads/pdf/100smokefreeprisons.pdf [Accessed $30 \mathrm{Jan}$ 2020].

69 From: RotsipDGfhaCDpahrSC-SFoRA.

70 Frank MR, Blumhagen R, Weitzenkamp D, et al. Tobacco use among people who have been in prison: relapse and factors associated with trying to quit. J Smok Cessat 2017;12:76-85 https://dx.doi.org/

71 Cropsey KL, Kristeller JL. The effects of a prison smoking ban on smoking behavior and withdrawal symptoms. Addict Behav 2005;30:589-94. 
72 Lincoln T, Tuthill RW, Roberts CA, et al. Resumption of smoking after release from a tobacco-free correctional facility. J Correct Health Care 2009;15:190-6.

73 Thibodeau L, Jorenby DE, Seal DW, et al. Prerelease intent predicts smoking behavior postrelease following a prison smoking ban. Nicotine Tob Res 2010;12:152-8.

74 Howell BA, Guydish J, Kral AH, et al. Prevalence and factors associated with smoking tobacco among men recently released from prison in California: a cross-sectional study. Addict Behav 2015;50:157-60.
75 Valera P, Bachman L, Rucker AJ. A qualitative study of smoking behaviors among newly released Justice-Involved men and women in New York City. Health Soc Work 2016;41:121-8.

76 Puljevic C, Segan CJ. Systematic review of factors influencing smoking following release from smoke-free prisons. Nicotine Tob Res 2018.

77 de Andrade D, Kinner SA. Systematic review of health and behavioural outcomes of smoking cessation interventions in prisons. Tob Control 2016;26:495-501. 